Aggregate consumer ratings and booking intention: the role of brand image

\author{
Ana B. Casado-Díaz \\ University of Alicante \\ E-mail: ana.casado@ua.es \\ Leonor M. Pérez-Naranjo \\ University of Cordoba \\ E-mail: 1perez@uco.es \\ Ricardo Sellers-Rubio \\ University of Alicante \\ E-mail: ricardo.sellers@ua.es
}

This article has been accepted for publication in:

Casado-Diaz, A.B., Pérez-Naranjo, L. y Sellers-Rubio, R. (2017) “Aggregate consumer ratings and booking intention: the role of brand image". Services Business, 11(3): 543-562. DOI: 10.1007/s11628-016-0319-0 


\title{
Aggregate consumer ratings and booking intention: the role of brand image
}

\begin{abstract}
The very nature of tourist services implies that consumers consider all available cues when making hotel bookings. Information obtained via the Internet is an especially important cue, and the findings of numerous studies highlight the importance of peer-generated information - electronic word-of-mouth (eWOM) - in consumers' decision-making processes. Along with eWOM, however, traditional marketing signals such as brand image and price still affect consumer behaviour. Thus, this study analyses the effect of eWOM (i.e. global hotel ratings) on purchase intention, considering the role of brand image. Two online scenario-based experiments designed using real information from TripAdvisor were conducted. The final sample comprised 260 participants. Variation in hotel ratings modified consumers' purchase intentions, with brand image playing a significant role in this relationship. The effect of eWOM on consumer purchase intentions was higher (lower) for hotels with a poorer (better) brand image. The results of the analysis imply that price can potentially help to prevent the negative effect of poor ratings.
\end{abstract}

Keywords Online consumer reviews · eWOM ' Hotel brand ' Booking intentions · Hospitality management 


\section{Introduction}

The widespread use of Internet technology has changed the way consumers choose and book hotels (Xie et al. 2011). Increasingly, travellers access the Internet to book hotel rooms via third-party intermediaries (Line and Runyan 2012). The term 'electronic intermediaries' (sometimes referred to as 'eMediaries') covers a range of organizations, including infomediaries, that let users exchange information through electronic word-of-mouth (eWOM) (Aldebert et al. 2011). As a kind of user-generated content, eWOM consists of various forms of publicly available media content created by end users. The importance of this peer-generated information in consumer decisions and preferences is widely accepted in the tourism industry (Viglia et al. 2014), and it has revolutionized the way people search for information (Jang et al. 2012; Litvin et al. 2008).

In hospitality, consumers struggle to evaluate a service before consumption because of its inherent intangibility, inseparability and heterogeneity (Grönroos 1990). These characteristics of the hospitality service increase the perceived risk in the purchase decision process (Sun 2014). Thus, consumers use all available evaluative cues to reduce perceived risk when making a purchase decision. Among these cues, information from infomediaries is especially relevant in the hotel industry during the pre-purchase stage (Serra-Cantallops and Salvi 2014) because many travellers consult third-party review sites before booking hotel rooms (Anderson 2012).

The wide variety of information available on websites, however, is often overwhelming for consumers, and choosing the right service online can be exhausting (Kostyra et al. 2016). Thus, consumers consider additional marketing signals and cues to help them to determine service attributes when purchasing a service (Sun 2014; Wu et al. 2012). In fact, the risk associated with buying decisions drives consumers to gather additional information (Murray 1991) that could affect how eWOM influences their purchase decisions. Understanding how eWOM affects customers' behaviour and interacts with other cues is a major challenge for academics and managers. Yet most studies neglect the potential influence of other variables that are nonetheless also important in helping customers to mitigate uncertainty when making purchase decisions. Few papers analyse the effect of interactions between eWOM and other cues (e.g. Ho-Dac et al. 2013; Lovett et al. 2013; Noone and McGuire 2014). The present study contributes to this research stream.

Two traditional signals and cues are considered in this paper: the hotels brand's reputation and prices. The hotel brand's reputation is among the most important signals. A hotel with a good brand image is more credible, and consumers will perceive less risk and will be more willing to purchase (Wu et al. 2012). Even when consumers have not directly experienced a product or service, exposure to the brand name creates a certain degree of familiarity (Grewal et al. 1998) so that consumers can make inferences about quality (Zeithaml 1988). In online environments, Lee and Tan (2003) reported that consumers tend to shop for products with strong brand names. Price is another signal used by consumers to infer service quality and perceived risk in the context of asymmetric information. Accordingly, price can also have an important impact on consumer purchase intention. Several authors (e.g. Chang and Wildt 1994; Dodds et al. 1991; Noone and McGuire 2014) have studied the effect of price on consumers' pre-purchase reactions in the presence of other signal and cues, showing that its effect is lower as other signals and cues arise. In the hospitality context, Noone and McGuire (2014) found that when price and user-generated content (both written reviews and aggregate ratings) are available to the consumer, user-generated content dominates price in terms of consumers' pre-purchase quality perceptions.

Hence, this paper responds to the growing need to understand how different elements of online information searching and booking influence consumer behaviour, mainly the 
propensity to book a hotel room (Vermeulen and Seegers 2009). The current paper contributes to the literature by examining the effect of interactions between eWOM and brand and price within the context of a service business. Gaining a better understanding of how these factors influence consumers' booking behaviour under realistic conditions is relevant for both practitioners and academics.

The aim of this research is to analyse the influence of eWOM on consumers' purchase intentions to book a hotel room. We also consider the effect of brand image. Our inclusion of brand image as a moderating variable adds to the literature on purchase intention, enriching this stream of research on eWOM in the hospitality industry. This research also considers the effect of price, which is an indicator of the sacrifice needed to purchase a product and of quality, both of which affect the perceived risk and, consequently, purchase intention.

To achieve these goals, the rest of the paper is organized as follows. Section 2 presents a review of relevant literature and develops the central hypotheses. Section 3 articulates the method and explains the empirical approach. Section 4 presents the main results. Section 5 describes the principal conclusions and managerial implications.

\section{Literature review}

\subsection{The importance of electronic word-of-mouth (eWOM)}

One of the factors consumers consider in their decision-making processes is word-of-mouth (WOM), defined as 'informal, person-to-person communication between a perceived noncommercial communicator and a receiver regarding a brand, product, an organization, or a service' (Harrison-Walker 2001, p.63). The importance of WOM has long been a relevant topic for marketing researchers and practitioners (Gruen et al. 2006) because customers often rely on word-of-mouth recommendations to influence many types of purchase decisions (Hess and Ring 2015).

The Internet revolution has profoundly changed the way information is distributed (Buhalis and Law 2008) and has given rise to a new form of WOM: electronic WOM (eWOM). According to Litvin et al. (2008, p.461), eWOM can be defined as 'all informal communications directed at consumers through Internet-based technology related to the usage or characteristics of particular goods and services, or their sellers'. Although WOM and eWOM are conceptually similar in terms of interpersonal influence, eWOM is more influential because of its accessibility (Chatterjee 2001), one-to-many reach, speed of interaction, convenience, and absence of face-to-face human pressure (Sun et al. 2006).

In the electronic environment, consumers can easily share their opinions on companies, products and services with other Internet users while potential customers can easily access these online reviews (Dellarocas 2003) on an unprecedented scale in real time. Nevertheless, the proliferation of consumer reviews on the Internet means that consumers face the complicated task of filtering and analysing this information (Zhan et al. 2009). Hence, many websites that support eWOM communications provide easy-to-process information such as aggregate customer ratings (e.g. 1-5 star ratings). These ratings summarize the texts, provide an average of individual consumers' evaluations and act as indicators of product quality (Noone and McGuire 2014; Tsang and Prendergast 2009).

The influence of eWOM is especially strong in the tourism industry (Papathanassis and Knolle 2011). Litvin et al. (2008) reported that eWOM is the most important source of information when consumers are deciding to purchase hospitality and tourism services. In addition, social interactions play a major role in the online travel community (Sigala 2012; Xiang and Gretzel 2010). Several studies have shown that online consumer reviews 
significantly affect consumer decision-making and purchasing processes and therefore influence product performance (Chevalier and Mayzlin 2006).

In general, scholars have conducted either market-level or individual-level studies (Lee and Lee 2009). At the market-level, eWOM has been linked to other market outcomes such as sales and revenues. Generally, market-level studies use an econometric approach with secondary data on reviews (e.g. average rating, dispersion of ratings and volume of reviews) collected from websites to examine the effect of eWOM on product sales (e.g. Ye et al. 2011). Individual-level studies, in contrast, take eWOM as being related to individual-level parameters such as purchase intention, attitude, information adoption and trust (Mauri and Minazzi 2013; Sparks and Browning 2011; Sparks et al. 2013; Vermeulen and Seegers 2009; Xie et al. 2011). Most of these (experimental) studies have analysed written comments rather than aggregated ratings, and valence (positive or negative) has been one of the most widely considered variables.

Several studies have shown that negative information usually has a stronger influence than either neutral or positive information does (Herr et al. 1991; Xie et al. 2011). Herr et al. (1991) found that negative reviews tend to be more diagnostic or informative than positive or neutral reviews are. The more informative nature of negative reviews may be a consequence of the loss aversion principle in prospect theory (Kahneman and Tversky 1979), which asserts that a potential loss affects consumer perceptions and decision-making more than an equivalent gain does because the value function is steeper for losses than it is for gains. Xie et al. (2011) reported that even when consumers initially have a positive impression of the hotel, negative eWOM is more powerful than positive eWOM is in influencing consumers' booking intentions. Conversely, some studies have shown that positive information exerts a stronger influence on brand choice than negative information does (East et al. 2008). Vermeulen and Seegers (2009) found that while all reviews (positive or negative) increase consumers' awareness of a hotel's existence, negative reviews actually worsen consumer attitudes. Nonetheless, the awareness of the hotel generated by eWOM compensates for the effect of negative reviews, particularly if the number of negative reviews is low.

Regarding aggregate consumer ratings, several authors (Chen 2008; Sparks and Browning 2011) have suggested that categorical rating information has a greater effect on product purchase decisions than detailed information does. Further, consumer confidence in aggregate consumer ratings rises as the number of reviews increases (Park et al. 2007) because a larger number of ratings indicates stronger objectivity and widespread familiarity with the product (Hong and Park 2012). Regarding valence, Hong and Park (2012) reported that negative statistical information is perceived as more credible than negative narrative comments are, whereas the credibility of positive statistical information is the same as that of positive narrative comments. Viglia et al. (2014) found that consumer preference for a hotel increases with the number of comments, regardless of whether the average rating is high or low. This result is mediated by demographics: young people - especially men - are less influenced by popularity, instead relying on quality.

Noone and McGuire (2014) reported that consumers rely more on comments than on ratings when evaluating price-benefit trade-offs, probably because of the diagnostic capabilities of comments - in terms of both capturing recent product/service changes and providing information quality (information relevance). In fact, consumers struggle to detect whether an overall rating reflects an assessment of the service attributes they consider relevant. When reading narrative reviews, however, consumers can easily focus on comments that are important to them and that offer pertinent insights into service attributes, dismissing comments that are irrelevant to the purchase decision.

In an attempt to integrate these two streams of research, Noone and McGuire (2014) suggested that the importance of written reviews and aggregate ratings might vary at each 
stage of the decision-making process. Consumers may use aggregate ratings to choose a consideration set, and then focus on the selection within that consideration set to obtain qualitative review data. According to Viglia et al. (2014), the consumer starts a hotel search by inserting the desired destination and dates of travel to yield a list of available hotels (the total set). In infomediaries like TripAdvisor.com, the consumer continues the search process by removing irrelevant hotels according to their aggregate rating and number of reviews to yield a smaller list of hotels (consideration set). The consumer then further examines some of these hotels by clicking on their icon to obtain additional information (e.g. cleanliness, staff, location, price and detailed reviews by consumers). The outcome of this stage is a smaller 'choice set' from which the consumer makes the final decision of which hotel to book. Jones and Chen (2011) found support for this theory in a recent empirical study, reporting that hotel consideration sets contain 10 hotels on average, whereas choice sets contain four hotels on average. This funnelling process helps consumers to choose a hotel by building a small set of comparable alternatives.

The literature review in this section shows that both positive and negative eWOM influences consumer behaviour. We therefore propose the following hypotheses:

H1a The higher the aggregate eWOM ratings of a hotel, the higher the customers' intention to book the hotel.

H1b The lower the aggregate eWOM ratings of a hotel, the lower the customers' intention to book the hotel.

\subsection{Brand image in the influence of ratings on booking intention}

The risk associated with purchasing drives consumers to gather additional information on products (Murray 1991). Particularly, the intangibility and experiential nature of services contributes to high consumer uncertainty about service offerings (Grönroos 1990).

In general, consumers rely on several extrinsic cues for quality inference and risk reduction when purchasing products (Huang et al. 2004). This occurs in situations where the consumer lacks adequate information about intrinsic product attributes or where intrinsic product attributes are too disparate to evaluate (Rao and Monroe 1988; Shimp and Bearden 1982). According to Bensebaa (2004), cues for judging products or services may be intrinsic or extrinsic. Intrinsic cues represent product-related attributes that cannot be manipulated without altering the product's physical properties. On the contrary, extrinsic cues are productrelated attributes external to the physical product (Richardson et al. 1994). Although intrinsic cues play a major role in purchase decisions (Bensebaa 2004), the nature of services means that consumers depend more on extrinsic cues than on intrinsic cues when purchasing services.

In the hotel industry, there are two kinds of extrinsic cues: cues under the hotel's control (e.g. brand image, five-star rating systems and room rates) and cues outside the hotel's control (e.g. user-generated content). Research has shown that eWOM may be more relevant and credible and may evoke more empathy in customers than information generated by marketers on the Internet (Bickart and Schindler 2001; Gretzel and Yoo 2008; Park et al. 2007). This preference arises because consumers suppose that consumer-generated content is more honest (Park et al. 2007), is free from marketers' interests and is user oriented (Bickart and Schindler 2001). Cox et al. (2009) showed that $73 \%$ of respondents prefer to read consumer reviews about a hotel than to rely on a hotel's description of itself. Five-star rating systems focus on evaluating physical attributes but are not always reliable, and each country selects its own ratings standards (Yacouel and Fleischer 2012). Many global hotel firms have thus 
successfully built attractive company reputations and brand images to prospective consumers when they consider purchasing a hotel service (Sun 2014).

Brand image, often defined as 'perceptions about a brand as reflected by the brand associations held in consumer memory' (Keller 1993, p.3), is one of the most effective riskreducing strategies used by consumers (Roselius 1971). Consumers are likely to reduce product performance risk by purchasing products from well-known brands. A brand name acts as a cue for quality because potential consumers can make quality inferences based upon the brand name (Zeithaml 1988). Therefore, because a brand name positively affects purchasers' perceptions of product quality (Grewal et al. 1998), a favourable product brand image positively affects purchase intentions (Keller 1993). Consumers are also more likely to shop online for products with strong brand names (Lee and Tan 2003). In this vein, Loureiro and Kastenholz (2011) argue that corporate reputation plays a pivotal role in customers' perceptions of service performance capability and consequently leads to a reliable representation of the service in the customer's mind. If a service provider has a good reputation, consumers tend to perceive it as having the ability to offer a good service. Andreassen and Lindestad (1998) argue that a good corporate reputation helps to maintain stable customer relationships and reduces quality uncertainty, thereby positively affecting consumers' purchasing intentions.

Crucially, well-established attitudes are resilient to change (Ahluwalia et al. 2000; Pomerantz et al. 1995). Consumers are unlikely to change their attitudes towards familiar brands (Hoyer and MacInnis, 1997). Higher levels of brand familiarity, gained through direct or indirect experiences, are associated with a well-developed knowledge structure about the brand and its attributes (Alba and Hutchinson 1987). As reported by Sundaram and Webster (1999), when the consumer has a pre-existing brand evaluation, the exposure of this brand to WOM is unlikely to produce significant attitude changes. In contrast, East et al. (2008) showed that positive comments increase customers' purchasing intentions regarding a familiar brand but that negative comments do not significantly decrease such intentions. Nonetheless, consumers are more likely to change their attitudes towards less familiar brands when they are exposed to new brand-related communications. Consumers that are less familiar with a brand are more prone to processing new brand-related information and changing their brand evaluations based on the nature of the information (Park and Lee 2009). In this sense, Sundaram and Webster (1999) demonstrated that consumers' evaluations of an unfamiliar brand are more susceptible to change from WOM than their attitudes towards a familiar brand are. Along the same lines, Vermeulen and Seegers (2009) showed that familiar hotel brands are resilient to the effects of online hotel reviews. Online reviews improve awareness and enhance persuasion more for lesser-known hotels than they do for well-known hotels. Following this line of reasoning, we hypothesize the following:

H2a The higher the aggregate eWOM ratings of a hotel with a relatively poor reputation, the greater the positive impact of such ratings on consumers.

H2b The lower the aggregate eWOM ratings of a hotel with a relatively poor reputation, the greater the negative impact of such ratings on consumers.

\section{Method}

\subsection{Procedure and data collection}

To investigate the interplay between brand image and online reviews (eWOM), we conducted two scenario-based experiments. This approach overcame the difficulties associated with observing real decisions in the field, and reduced biases derived from memory lapses 
(compared to retrospective self-reports) (Grewal et al. 2008, p. 428). We designed scenarios using real information from TripAdvisor (www.tripadvisor.com). TripAdvisor is one of the world's largest travel websites. It reaches 350 million unique monthly visitors and contains more than 300 million reviews and opinions from real travellers, covering more than 6.2 million accommodations, restaurants and attractions (TripAdvisor, 2016). Recent research has emphasized TripAdvisor's growing importance for consumers with regard to online (usergenerated) reviews in the hospitality industry (Anderson 2012; Gretzel and Yoo 2008; O’Connor 2010).

The first experiment followed a 2 (brand: Medium vs. Meliá) x 2 (review rate: 3.5, 4.5) within-subjects factorial experimental design, allowing us to test hypotheses 1 and 2. In this experiment, hotel prices were held constant. To determine the potential effect of hotel prices on the relationship between review ratings and purchase intention, we designed a second experiment. The second experiment also had a $2 \times 2$ factorial design but, in this case, the hotel room prices changed as well as ratings.

We collected data using an online survey, which has been successfully employed in recent hospitality and tourism research (see Hung and Law 2011 for a review). One advantage of online surveys is that they help to minimize social desirability bias (Duffy et al. 2005). Nevertheless, they fail to prevent form response style bias. We therefore randomly presented the different scenarios to respondents to avoid the tendency for respondents to agree with items regardless of the content. In addition, we employed a reversed item to estimate brand image (estimated with a multiple item scale), as per Vaerenbergh and Thomas' (2013) suggestions. The goal of the study was to identify relationships among variables, so we followed Weijters et al.'s (2010) suggestions and used the endpoint-labelled 5-point rating scale, which yields lower rates of acquiescence response style. The questionnaire was pretested on a sample of 15 respondents. Based on the pre-test, tiny modifications were made to improve the structure and flow of the questionnaire. The survey was launched in November 2014. The population comprised all Spanish Internet users aged 18 or older because these consumers exhibit a tendency to book hotels online. Because of the absence of a list of Spanish Internet users, however, we were unable to select our sampling elements directly from the population. Consequently, we used a non-probabilistic sampling procedure convenience sampling - to collect our data. The survey was promoted through blogs, e-mail and social networks. We administered the experiment online to make the stimulus material as realistic as possible.

First, the survey asked respondents whether they had used the Internet to search for travel information and/or whether they had bought any tourism service (e.g. flights, hotels) in the 12 months prior to the study. We included this question to ensure respondents were familiar with recent Internet booking procedures and options. The survey ended immediately if respondents answered negatively to this question. Participants were randomly assigned to one of the two experiments. From the initial 405 respondents, 260 complete responses (125 in the first experiment and 135 in the second experiment) were obtained.

\subsection{Stimulus materials}

We designed a stimulus to help respondents to form their booking intentions towards the hotels. First, the questionnaire instructed respondents to imagine searching for a hotel for a weekend stay (one night) in a well-known Spanish location and to decide between two hotels: Meliá Hotel and Medium Hotel. Both are hotel chains operating in the same segment in Spain, although customers' knowledge of each brand differs. Whereas Meliá Hotel is a well-known and familiar brand (it has forty-three hotels in Spain, with two in the chosen city), Medium Hotel is not that popular (it has just four hotels in Spain, with only one in the chosen city). Both hotels were well located in the city centre and had four stars according to the official 
hotel star ratings (from 1 to 5). These two conditions avoided any confounding effects that might arise from location or category (which are common considerations when booking hotels).

The questionnaire instructed respondents to look at different scenarios and explicitly warned respondents that room prices and hotel ratings would change from one scenario to another. This statement was included in the instructions to respondents to meet the threshold of respondents' perceptions regarding change in ratings and prices. Respondents were also instructed to indicate their intention to book for each hotel in each scenario. The different scenarios were based on real screen captures from TripAdvisor. We generated these captures by searching for real hotels for a weekend stay in the chosen Spanish location. We then manipulated the real capture to eliminate confounding factors: we fixed the recent opinion to be the same in both hotels, and we eliminated any mention of location, special offers or quality prizes.

In the first experiment, the two hotels had different (real) prices (56 Euros for Medium Hotel and 93 Euros for Meliá Hotel) in the initial condition, but equal review ratings (the bubble rating and the thumb percentage). The bubble rating is an overall score accounting for travellers' ratings and reviews. It ranges from one bubble to five bubbles, where one bubble means 'terrible' and five means 'excellent'. The thumb percentage is the percentage of total reviews rated 4 or 5 . For both hotels, the initial condition set the bubble rating to 4.0 and the thumb rating to $79 \%$. For both hotel descriptions, respondents indicated their booking intentions.

Next, four pairs of descriptions of the two hotels were presented. In the first and second scenarios, the description of the Hotel Medium was set to the initial condition, but in the description of the Hotel Meliá, the average rating was manipulated to be higher than the initial condition $(91 \%$; 4.5$)$ in the first scenario and lower than the initial condition $(63 \% ; 3.5)$ in the second scenario. In the third and fourth scenarios, the description of the Hotel Melia was set to the initial condition, but in the description of the Hotel Medium, the average rating was manipulated to be higher than the initial condition $(91 \%$; 4.5$)$ in the third scenario and lower than the initial condition $(63 \% ; 3.5)$ in the fourth scenario. Each respondent was exposed to the five descriptions, the initial condition and the four scenarios. This experiment allowed us to test hypotheses 1 and 2 .

In the second experiment, the initial condition was the same as in the first experiment. Four pairs of descriptions of the two hotels were presented. In the first and the second scenarios, Hotel Medium's description was set to the initial condition, but the average rating and room prices were manipulated in Hotel Meliá's description to be higher than the initial condition $(91 \% ; 4.5 ; 105$ euros) in the first scenario and lower than the initial condition $(63 \% ; 3.5 ; 75$ euros) in the second scenario. In the third and fourth scenarios, Hotel Meliá's description was set to the initial condition, but in the description of the Hotel Medium, the average rating and room prices were manipulated to be higher than the initial condition $(91 \% ; 4.5 ; 62$ euros) in the third scenario and lower than the initial condition $(63 \% ; 3.5 ; 49$ euros) in the fourth scenario. Thus, each respondent was exposed to the five descriptions, the initial condition and the four scenarios.

Table 1 summarizes the different scenarios proposed in the two experiments.

\section{Take in Table 1}

Finally, respondents in both experiments answered control questions so that we could check the effectiveness of the stimulus materials, the general brand image of the hotels and respondents' demographic profile. 


\subsection{Measures}

All items were measured using 5-point scales. Booking intention was measured by asking respondents for their level of intent to book a stay at each hotel $(1=$ strongly unlikely to $5=$ strongly likely) (Mauri and Minazzi 2013; Sparks and Browning 2011).

The study used two items to check the realism of the scenarios: 'How would you describe the realism of the scenarios presented?' $(1=$ very unrealistic to $5=$ very realistic $)$ and 'I have no difficulty imagining this situation' $(1=$ strongly disagree to $5=$ strongly agree $)$ (Dabholkar and Bagozzi 2002). Finally, to verify respondents' perceptions in terms of brand image, the study used three items $(1=$ strongly disagree to $5=$ strongly agree $)$ : 'Meliá Hotels have a better brand image than Medium Hotels do', 'I can trust Meliá Hotels more than I can trust Medium Hotels', and 'Medium Hotels have a better reputation than Meliá Hotels do'. These scales were adapted from Serić and Gil (2012).

\section{Results}

Table 2 contains descriptive information of the study sample. Most respondents were aged between 35 and 54 (66.15\%) and had an average monthly income of between 1,000 and 2,500 Euros (64.62\%). Most respondents were university educated (87.69\%). In terms of gender, $58.85 \%$ were men and $41.15 \%$ women. The Analysis of Variance (ANOVA) tests yielded no differences in booking intentions in terms of age, gender or educational attainment in any scenario. Regarding monthly income, ANOVA tests yielded no differences in most scenarios.

\section{Take in Table 2}

Manipulation checks indicated that the stimuli were effective in both experiments. Respondents felt that the scenarios were realistic $(\operatorname{Exp} 1 M=3.61, \mathrm{SD}=0.85 ; \operatorname{Exp} 2 M=3.53$, $\mathrm{SD}=0.98)$, and they had no difficulty imagining the situation described $(\operatorname{Exp} 1 M=4.30, \mathrm{SD}$ $=0.83 ; \operatorname{Exp} 2 M=4.16, \mathrm{SD}=0.96)$. Regarding brand image, we tested whether the average response of the sample differed significantly from the mean value for the scale. For the first two items, we tested whether the average response of the sample was significantly higher than 3 (i.e. the mean value for the scale). The first item stated, 'Meliá Hotels have a better brand image than Medium Hotels do' $(\operatorname{Exp} 1 M=3.91, \mathrm{SD}=1.02, t=9.86 ; p<0.00 ; \operatorname{Exp} 2 M=$ $3.96, \mathrm{SD}=1.00, t=11.11 ; p<0.00)$. The second item stated, 'I can trust Meliá Hotels more than I can trust Medium Hotels' (Exp1 $M=3.39, \mathrm{SD}=1.11, t=3.91 ; p<0.00 ; \operatorname{Exp} 2 M=$ $3.47, \mathrm{SD}=1.04, t=5.24 ; p<0.00)$. The third item was reversed, so we tested if the average response of the sample was significantly lower than 3: 'Medium Hotels have a better reputation than Meliá Hotels do' $(\operatorname{Exp} 1 M=2.55, \mathrm{SD}=0.95, t=-5.21 ; p<0.00$; Exp2 $M=$ 2.33, $\mathrm{SD}=0.97, t=-8.00 ; p<0.00)$. In both experiments, results confirmed that Meliá Hotels had a better brand image and reputation than Medium Hotels did.

Table 3 shows the means for booking intentions by condition. The results indicated that Medium Hotel achieved higher booking intention levels than did Meliá Hotel in all the scenarios presented in experiment 1 , including the initial condition where average ratings were set to equal levels in both hotels. Seemingly, the price effect was greater than the brand effect was. This finding is consistent with previous research indicating that less expensive hotels tend to receive more online bookings (Ye et al. 2011). In experiment 2, the results also indicated that Medium Hotel achieved higher booking intention levels than did Meliá Hotel in the initial condition where average ratings were set to equal levels. Furthermore, Medium 
Hotel achieved higher booking intention levels than Meliá Hotel did in all scenarios, except scenario 1.

\section{Take in Table 3}

Hypotheses $1 \mathrm{a}$ and $1 \mathrm{~b}$ postulate that booking intentions are higher (lower) when average ratings (eWOM) increase (decrease). These hypotheses were tested in experiment 1, where hotel prices were held constant. We performed t-tests to compare initial conditions to the four scenarios (see Table 4). As the scores in the five conditions in experiment 1 were from the same subjects, we used correlated t-tests. Responses indicated that when average ratings were high (low), booking intentions were significantly higher (lower) than they were for initial conditions. All t-values were significant $(p<0.001)$, thereby supporting hypotheses $1 \mathrm{a}$ and $1 b$. This result supports the idea that review ratings have an effect on purchase intention. As Chevalier and Mayzlin (2006) state, online consumer reviews affect consumer decisionmaking and purchasing processes. This result is especially important in the context of tourist services, where the consumer cannot asses the quality of the service before consuming the service.

To analyse the conjoint effect of hotel prices and review ratings, experiment 2 was designed so that the hotel room prices changed as well as ratings. As in experiment 1, responses indicated that when average ratings were high, booking intentions were significantly higher than they were for initial conditions. All t-values were significant $(p<$ 0.01). When average ratings were low, however, although booking intentions were lower than they were for initial conditions, not all t-values were significant. Notably, the difference was not statistically significant $(t=-0.09 ; p>0.01)$ in the case of low average ratings for Meliá Hotel. This result implies that when the rating is low, Meliá Hotel can offset the expected lower booking intention by reducing its prices.

\section{Take in Table 4}

Hypotheses $2 \mathrm{a}$ and $2 \mathrm{~b}$ posit that while eWOM always affects booking intentions, this effect should be stronger in the case of Medium Hotel because its brand image was worse than Meliá Hotel's. To avoid confounding price effects, these hypotheses were tested with experiment 1, where hotel prices were held constant in all scenarios. We first performed correlated t-tests to compare booking intentions between the two hotels in the four scenarios (see Table 5). The results indicated that Medium Hotel achieved higher booking intention levels than did Meliá Hotel in all scenarios, except scenario 1 in experiment 2. Hotel mean differences were significant in all scenarios $(p<0.00)$. Once the differences between the hotel booking intentions were confirmed, we performed t-tests to determine whether the effect of increases (decreases) in average ratings differed depending on the hotel examined (i.e. brand reputation effect). We compared scenario 1 with scenario 3 and scenario 2 with scenario 4 to check for significant differences between the mean differences. The survey data indicated that when average ratings increased (decreased), the positive (negative) effect on Medium Hotel was greater than it was on Meliá Hotel, thereby supporting hypotheses $2 \mathrm{a}$ and $2 \mathrm{~b}$ (see the last column in Table 5). The same results apply in experiment 2 . This finding is consistent with previous research showing that familiar hotel brands are more resilient to review effects than unfamiliar brands are (Chatterjee 2001; Vermeulen and Seegers 2009).

\section{Take in Table 5}




\section{Discussion and conclusions}

Information and communication technologies (ICTs) have been revolutionizing the tourism industry since the 1980s (Buhalis and Law 2008; Leung et al. 2013), thereby positively contributing to the hospitality industry (Ruiz-Molina et al. 2011). Growing numbers of travellers use the Internet to book hotel rooms via third-party intermediaries (Line and Runyan 2012) that let users exchange information through eWOM. These infomediaries usually post both statistical and narrative consumer reviews.

Consumers' quantitative assessment of their experience is an important cue that supports decision-making by potential consumers (Chen 2008), especially when selecting hotel consideration sets (Viglia et al. 2014). This rating summarizes the narrative review and provides potential customers with a shortcut to assessing and evaluating a product or service (Tsang and Prendergast 2009). Along with this information, traditional marketing signals such as brand image still affect consumer behaviour. However, despite the ever-growing literature in this field, no studies have yet focused on analysis of the combined effects of 'new' information cues (online reviews) and 'traditional' information cues (brand image) on booking intention. Thus, this study's aim was to analyse how aggregate consumer ratings affect hotel booking intentions, considering the role of brand image.

Our results for an online experiment with Spanish consumers reveal that purchase intentions depend on the eWOM gathered. Notably, hotel ratings modify consumers' purchase intentions. Furthermore, brand image plays a significant role in this relationship. Specifically, eWOM's effect on consumer purchase intentions is higher (lower) for hotels with a poorer (better) brand image. Results also show that price can potentially counteract the negative effect of poor hotel ratings.

\subsection{Contributions to scholarship}

The findings of this research confirm the persuasive effect and the detrimental impact of high and low ratings, respectively, on consumers' purchase intentions (Chatterjee 2001; Sparks and Browning 2011; Ye et al. 2011) because hotel aggregate ratings and hotel booking intentions are positively related.

Our findings highlight the importance of eWOM in the tourism industry, reinforcing the belief that online consumer reviews significantly affect consumer decision-making and purchasing processes (Chevalier and Mayzlin 2006). Understanding how eWOM affects customers' behaviour and interacts with other cues is a major challenge for academics. Nevertheless, the literature largely neglects the potential influence of other variables and their interactions with eWOM, and few studies have actually analysed the effects of interactions between eWOM and other cues (e.g. Ho-Dac et al. 2013; Lovett et al. 2013; Noone and McGuire 2014). The current study contributes to this research stream by analysing the interactions between eWOM and brand image and price. First, results suggest that a strong hotel brand means that the hotel's customers are less sensitive to aggregate customer ratings. Likewise, eWOM matters less in the presence of a strong brand. Consistent with previous research on persuasive communication, our findings show that strong attitudes are resilient to change (Ahluwalia et al. 2000; Pomerantz et al. 1995). This finding is consistent with prior research findings in this field (Ho-Dac et al. 2013; Vermeulen and Seegers 2009). Consumers feel assured of obtaining high-quality service and reduce their perceptions of risk if they choose a highly reputable hotel (Sun 2014). In fact, a service provider's reputation is based on the service provider's ability to supply high-quality products or services. Thus, brand image is still a relevant factor in establishing customer relationships. Second, although Chang and Wildt (1994) suggest that the effect of price on quality perceptions varies inversely with the perceived information value of other available cues, our findings show that price potentially 
counteracts the negative effect of poor hotel ratings. When the brand's online reputation (i.e. the brand's rating) is low, a reduction in price can offset the expected lower booking intention.

\subsection{Managerial implications}

Representing a powerful new communication and distribution channel for travel suppliers, the Internet has altered both the tourism industry and travellers' behaviour (Buhalis and Law 2008). Tourists have high expectations for service quality and accommodation experiences (Tang et al. 2015) and form these expectations using intrinsic and extrinsic cues that indicate likely performance standards (Gould-Williams 1999). Today's consumers trust websites with reviews more than they trust professional guides and travel agencies, which are in turn more credible and trustworthy than traditional marketing communications (Akehurst 2009). Through websites like Tripadvisor.com, travellers can comment on products and destinations they have experienced. Consumer-generated online reviews inform and influence future travellers, who consider this information when making their purchase decisions (Gretzel and Yoo 2008; Jang et al. 2012; Xiang and Gretzel 2010). In fact, reading other consumers' comments is one of the most common online travel-related activities. Thus, understanding how this peer-generated information influences consumer behaviour represents a key challenge for managers. The findings of our study have several managerial implications.

The first managerial implication is that hotel managers should encourage positive consumer assessments and improve low ratings by providing a high level of service quality and by performing satisfactory and timely service recoveries (Zeithaml et al. 2006). Furthermore, hotel managers should monitor consumers' detailed online reviews to understand consumers' criticisms of the hotel. Managers can then draw on information from positive reviews and develop actions to defend the hotel from negative reviews. Examining the drivers of negative online reviews is essential to learn from mistakes and identify areas for improvement. Managers can also understand the type and standard of service that consumers expect (Mauri and Minazzi 2013). Implementing the right type of customer expectation management is crucial because overselling the qualities of a product or service might prove counter-productive (Kostyra et al. 2016).

Proper eWOM management mainly benefits lesser-known hotels because the gain or loss from eWOM improvement or deterioration is much greater for lesser-known hotels than it is for hotels with strong brand images. Hence, although small hotels are less resource rich than larger hotels are, small firms can use their proximity to the consumer and their ability to quickly adapt to capitalize on eWOM's effects. The challenge is to achieve a high initial rating to overcome the brand's deficit. Thus, stimulating satisfied customers to share their experience is important (Bigné et al. 2015), as is preventing negative eWOM, particularly because an unsatisfactory experience provokes more eWOM than a satisfactory experience does (Terblanche 2015).

According to Ho-Dac et al. (2013), greater positive eWOM aids a brand's transition from weak to strong by creating a positive feedback loop between sales and positive eWOM. Building a strong brand image is imperative for hotel managers (Sun 2014). Brand image is a crucial factor that determines perceived quality, satisfaction and loyalty (i.e. intention to return, recommend and even pay more) (Loureiro and Kastenholz 2011). Loyal customers who stay with a brand because of emotional benefits are more likely to ignore both other brands and negative eWOM related to their preferred brand (Kostyra et al. 2016). One way to strengthen the relationship between a brand and its audience is to employ social media, which can strengthen the relationship with customers and build brand loyalty. Finally, managers can use ratings as an indicator for price changes because price reductions can offset a decline in ratings. 


\subsection{Limitations and future research}

Like all studies, this research has some limitations. First, existing research has examined many other factors that relate to the influence of eWOM on hotel performance. These include, among others, additional secondary data on reviews (e.g. volume of reviews, written comments or valence) and reviewers' expertise with the product. Future research should investigate whether these factors influence the relationships found herein and which ones are most influential at different purchase stages. A second limitation relates to the sample used in this study. Our results are limited to responses from online travel consumers in Spain, and caution must be exercised in any attempt to generalize the results to other populations and settings. Future research should replicate this study in other cultural contexts to validate our findings.

\section{References}

Ahluwalia R, Burnkrant R, Unnava H (2000) Consumer response to negative publicity: the moderating role of commitment. J Mark Res 37:203-214.

Akehurst G (2008) User generated content: the use of blogs for tourism organisations and tourism consumers. Serv Bus 3:51-61.

Alba JW, Hutchinson JW (1987) Dimensions of consumer expertise. J Consum Res 13:411-454.

Aldebert B, Dang RJ, Longhi C (2011) Innovation in the tourism industry: the case of Tourism@. Tour Manag 32:1204-1213.

Anderson C.K (2012) The impact of social media on lodging performance. Cornell Hosp Rep 12:6-11.

Andreassen TW, Lindestad B (1998) The effect of corporate image in the formation of customer loyalty. J Serv Res 1:82-92.

Bensebaa F (2004) The impact of strategic actions on the reputation building of e-businesses. Int J Retail Distrib Manag 32:286-301.

Bickart B, Schindler RM (2001) Internet forums as influential sources of consumer information. J Interact Mark $15: 31-40$.

Bigné E, Ruiz C, Andreu L, Hernandez B (2015) The role of social motivations, ability, and opportunity in online know-how exchanges: evidence from the airline services industry. Serv Bus 9:209-232.

Buhalis D, Law R (2008) Progress in information technology and tourism management: 20 years on and 10 years after the internet - the state of etourism research. Tour Manag 29:609-623.

Chang TZ, Wildt AR (1994). "Price, product information, and purchase intention: An empirical study. J Acad Mark Sci 22:16-27.

Chatterjee P (2001) Online reviews: do consumers use them?. Adv Consum Res 28:129-133.

Chen Y (2008) "Herd behavior in purchasing books online. Comput Hum Behav 24:1977-1992.

Cox C, Burgess S, Sellitto C, Buultjens J (2009) The role of user generated content in tourists' travel planning behaviour. J Hospital Mark Manag 18:743-764.

Dabholkar PA, Bagozzi RP (2002) An attitudinal model of technology-based self- service: moderating effects of consumer traits and situational factors. J Acad Mark Sci 30:184-201.

Dellarocas C (2003) The digitization of word of mouth: promise and challenges of online feedback mechanisms. Manag Sci 49:1407-1424.

Dodds WB, Monroe KB, Grewal D (1991) Effects of price, brand, and store information on buyers' product evaluations. J Mark Res 18:307-319.

Duffy B, Smith K, Terhanian G, Bremer J (2005) Comparing data from online and face-to-face surveys. Int J Mark Res, 47:615-639.

East R, Hammond K, Lomax W (2008) Measuring the impact of positive and negative word of mouth on brand purchase probability. Int J Res Mark 25:215-224.

Gould-Williams J (1999) The impact of employee performance cues on guest loyalty, perceived value and service quality. Serv Ind J 19:97-118.

Gretzel U, Yoo KH (2008) Use and impact of online travel reviews. In O'Connor DP, Höpken DW, Gretzel DU (eds), Information and Communication Technologies in Tourism 2008. Springer, Vienna, pp 35-46.

Grewal D, Krishnan R, Baker J, Borin N (1998) The effect of store name, brand name, and price discounts on consumers' evaluations and purchase intentions. J Retail 74:331-352. 
Grewal D, Roggeveen AL, Tsiros M (2008) The effect of compensation on repurchase intentions in service recovery. J Retail 84:424-434.

Grönroos C (1990) Services marketing and management. Lexington Books, Lexington, MA.

Gruen TW, Osmonbekov T, Czaplewski AJ (2006) eWOM: the impact of customer-to-customer online knowhow exchange on customer value and loyalty. J Bus Res 59:449-456.

Harrison-Walker L.J (2001) The measurement of word of mouth communication and an investigation of service quality and customer commitment as potential antecedents. J Serv Res 4:60-75.

Herr PM, Kardes FR, Kim J (1991) Effects of word-of-mouth and product attribute information on persuasion: an accessibility-diagnosticity perspective. J Cons Res 17:454-462.

Hess RL, Ring L (2015) The influence of the source and valence of word-of-mouth information on post-failure and post-recovery evaluations. Serv Bus. In press. Published online 10-May-2015. DOI 10.1007/s11628015-0272-3

Ho-Dac NN, Carson SJ, Moore WL (2013) The effects of positive and negative online customer reviews: Do brand strength and category maturity matter? J Mark 77: 37-53.

Hong S, Park HS (2012) Computer-mediated persuasion in online reviews: statistical versus narrative evidence. Comput Hum Behav 28:906-919.

Hoyer WD, MacInnis D (1997) Consumer behaviour. Houghton Mifflin, Boston.

Huang WY, Schrank H, Dubinsky AJ (2004) Effect of brand name on consumers' risk perceptions of online shopping. J Cons Behav 4:40-50.

Hung K, Law R (2011) An overview of internet-based surveys in hospitality and tourism journals. Tour Manag 32:717-724.

Jang S, Prasad A, Ratchford BT (2012) How consumers use product reviews in the purchase decision process. Mark Lett 23:825-838.

Jones P, Chen MM (2011) Factors determining hotel selection: online behaviour by leisure travellers. Tour Hospital Res 11:83-95.

Kahneman D, Tversky A (1979) Prospect theory: an analysis of decisions under risk. Econometrica 47:263-292.

Keller KL (1993) Conceptualizing, measuring, and managing customer-based brand equity. J Mark 57:1-22.

Kostyra DS, Reiner J, Natter M, Klapper D (2016) Decomposing the effects of online customer reviews on brand, price, and product attributes. Int J Res Mark 33:11-26.

Lee J, Lee JN (2009) Understanding the product information inference process in electronic word-of-mouth: an objectivity-subjectivity dichotomy perspective. Inf Manag 46:302-311.

Lee KS, Tan SJ (2003) E-retailing versus physical retailing: a theoretical model and empirical test of consumer choice. J Bus Res 56:877-885.

Leung D, Law R, van Hoof H, Buhalis D (2013) Social media in tourism and hospitality: a literature review. J Travel Tour Mark 30:3-22.

Line ND, Runyan RC (2012) Hospitality marketing research: recent trends and future directions. Int J Hospital Manag 31:477-488.

Litvin SW, Goldsmith RE, Pan B (2008) Electronic word-of-mouth in hospitality and tourism management. Tour Manag 29:458-468.

Loureiro SMC, Kastenholz E (2011) Corporate reputation, satisfaction, delight, and loyalty towards rural lodging units in Portugal. Int J Hospital Manag 30:575-583.

Lovett, MJ, Peres R, Shachar R (2013) On brands and word of mouth. J Mark Res 50:427-444.

Mauri AG, Minazzi R (2013) Web reviews influence on expectations and purchasing intentions of hotel potential customers. Int J Hospital Manag 34:99-107.

Murray KB (1991) A test of services marketing theory: consumer information acquisition activities. J Mark $55: 10-25$.

Noone BM, McGuire KA (2014) Effects of price and user-generated content on consumers' prepurchase evaluations of variably priced services. J Hospital Tour Res 38:562-581.

O’Connor P (2010) Managing a hotel's image on TripAdvisor. J Hospital Mark Manag 19:754-772.

Papathanassis A, Knolle F (2011) Exploring the adoption and processing of online holiday reviews: a grounded theory approach. Tour Manag 32:215-224.

Park C, Lee TM (2009) Information direction, website reputation and eWOM effect: a moderating role of product type. J Bus Res 62:61-67.

Park DH, Lee J, Han I (2007) The effect of on-line consumer reviews on consumer purchasing intention: the moderating role of involvement. Int J Electron Commerce 11:125-148.

Pomerantz EM, Chaiken S, Tordesillas RS (1995) Attitude strength and resistance processes. J Pers Soc Psychol 69:408-419.

Rao AR, Monroe KB (1988) The moderating effect of prior knowledge on cue utilization in product evaluations. J Cons Res 15:253-264. 
Richardson PS, Dick AS, Jain AK (1994) Extrinsic and intrinsic cue effects on perceptions of store brand quality. J Mark 58:28-36.

Roselius T (1971) Consumer rankings of risk reduction methods. J Mark 35:56-61.

Ruiz-Molina ME, Gil-Saura I, Moliner-Velázquez, B (2011) Does technology make a difference? Evidence from Spanish hotels. Serv Bus 5:1-12.

Serić M, Gil I (2012) Relaciones causales entre las TIC, la CIM y el valor de marca: Un estudio a partir de las percepciones de los huéspedes. Papers de Turisme 52:1-21.

Serra-Cantallops A, Salvi F (2014) New consumer behavior: a review of research on eWOM and hotels. Int $\mathbf{J}$ Hospital Manag 36:41-51.

Shimp TA, Bearden WO (1982) Warranty and other extrinsic cue effects on consumers' risk perceptions. J Cons Res 9:38-46.

Sigala M (2012) Social networks and customer involvement in new service development (NSD): the case of www.mystarbucksidea.com. Int J Contemp Hospital Manag 24:966-990.

Sparks BA, Browning V (2011) The impact of online reviews on hotel booking intentions and perception of trust. Tour Manag 32:1310-1323.

Sparks B, Perkins H, Buckley R (2013) Online travel reviews as persuasive communication: the effects of content type, source, and certification logos on consumer behavior. Tour Manag 39:1-9.

Sun J (2014) How risky are services? An empirical investigation on the antecedents and consequences of perceived risk for hotel service. Int J Hospital Manag 37:171-179.

Sun T, Youn S, Wu G, Kuntaraporn M (2006) Online word-of-mouth: an exploration of its antecedents and consequences. J Comput-Mediat Commun 11:1104-1127.

Sundaram DS, Webster C (1999) The role of brand familiarity on the impact of word-of-mouth communication on brand evaluations. Adv Consum Res 26:664-670.

Tang, TW, Wang MCH, Tang YY (2015) Developing service innovation capability in the hotel industry. Serv Bus 9:97-113.

Terblanche NS (2015) Measuring word-of-mouth activity after a service encounter: are we measuring what customers communicate? Serv Bus. In press. Published online 29 January 2015. DOI 10.1007/s11628$015-0268-\mathrm{z}$

TripAdvisor (2016) TripAdvisor Fact Sheet. www.tripadvisor.com/PressCenter-c4-Fact_Sheet.html. Retrieved Feb 2016.

Tsang ASL, Prendergast G (2009) Is a star worth a thousand words? The interplay between product-review texts and rating valences. Eur J Mark 43:1269-1280.

Vermeulen IE, Seegers D (2009) Tried and tested: the impact of online hotel reviews on consumer consideration. Tour Manag 30:123-127.

Viglia G, Furlan R, Ladrón-de-Guevara A (2014) Please, talk about it! When hotel popularity boosts preferences. Int J Hospital Manag 42:155-164.

Wu CHJ, Liao HC, Hung KP, Ho YH (2012) Service guarantees in the hotel industry: their effects on consumer risk and service quality perceptions. Int J Hospital Manag 31:757-763.

Xiang Z, Gretzel U (2010) Role of social media in online travel information search. Tour Manag 31:179-188.

Xie H, Miao L, Kuo PJ, Lee BY (2011) Consumers' responses to ambivalent online hotel reviews: the role of perceived source credibility and pre-decisional disposition. Int J Hospital Manag 30:178-183.

Yacouel N, Fleischer A (2012) The role of cybermediaries in reputation building and price premiums in the online hotel market. J Travel Res 51:219-226.

Ye Q, Law R, Gu B, Chen W (2011) The influence of user-generated content on traveler behavior: an empirical investigation on the effects of e-word-of-mouth to hotel online bookings. Comput Hum Behav 27:634639.

Zeithaml VA (1988) Consumer perceptions of price, quality, and value: a means-end model and synthesis of evidence. J Mark 52:2-22.

Zeithaml VA, Bitner MJ, Gremler D (2006) Services marketing: integrating customer focus across the firm, 4th ed. McGraw-Hill, Boston, MA.

Zhan J, Loh HT, Liu Y (2009) Gather customer concerns from online reviews: a text summarization approach. Expert Sys App 36:2107-2115. 
Table 1

Summary of scenarios

\begin{tabular}{|c|c|c|c|c|c|c|c|c|c|c|c|c|}
\hline & \multicolumn{6}{|c|}{ Experiment $1(N=125)$} & \multicolumn{6}{|c|}{ Experiment $2(N=135)$} \\
\hline & \multicolumn{2}{|c|}{ Thumb \% } & \multicolumn{2}{|c|}{ Bubble rating } & \multicolumn{2}{|c|}{ Price $(€)$} & \multicolumn{2}{|c|}{ Thumb \% } & \multicolumn{2}{|c|}{ Bubble rating } & \multicolumn{2}{|c|}{ Price $(€)$} \\
\hline & MED & MEL & MED & MEL & MED & MEL & MED & MEL & MED & MEL & MED & MEL \\
\hline $\begin{array}{l}\text { Initial } \\
\text { Condition }\end{array}$ & $79 \%$ & $79 \%$ & 4 & 4 & 56 & 93 & $79 \%$ & $79 \%$ & 4 & 4 & 56 & 93 \\
\hline Scenario 1 & $79 \%$ & $91 \%$ & 4 & 4.5 & 56 & 93 & $79 \%$ & $91 \%$ & 4 & 4.5 & 56 & 105 \\
\hline Scenario 2 & $79 \%$ & $63 \%$ & 4 & 3.5 & 56 & 93 & $79 \%$ & $63 \%$ & 4 & 3.5 & 56 & 75 \\
\hline Scenario 3 & $91 \%$ & $79 \%$ & 4.5 & 4 & 56 & 93 & $91 \%$ & $79 \%$ & 4.5 & 4 & 62 & 93 \\
\hline Scenario 4 & $63 \%$ & $79 \%$ & 3.5 & 4 & 56 & 93 & $63 \%$ & $79 \%$ & 3.5 & 4 & 49 & 93 \\
\hline
\end{tabular}

Notes: MED-Medium Hotel; MEL-Meliá Hotel. The bubble rating is an overall score reflecting travellers' ratings and reviews. It ranges from one bubble to five bubbles, where one bubble means 'terrible' and five means 'excellent'. The thumb percentage is the percentage of total reviews rated 4 or 5 . 
Table 2

Descriptive profile of respondents

\begin{tabular}{|c|c|c|c|c|c|c|}
\hline \multirow[b]{2}{*}{ Characteristics } & \multicolumn{2}{|c|}{ Overall } & \multicolumn{2}{|c|}{ Experiment 1} & \multicolumn{2}{|c|}{ Experiment 2} \\
\hline & $N=260$ & $\%$ & $N=125$ & $\%$ & $N=135$ & $\%$ \\
\hline \multicolumn{7}{|l|}{ Age } \\
\hline $18-24$ & 15 & 5.77 & 8 & 6.40 & 7 & 5.20 \\
\hline $25-34$ & 55 & 21.15 & 25 & 20.00 & 30 & 22.20 \\
\hline $35-44$ & 104 & 40.00 & 53 & 42.40 & 51 & 37.80 \\
\hline $45-54$ & 68 & 26.15 & 29 & 23.20 & 39 & 28.90 \\
\hline$>55$ & 18 & 6.92 & 10 & 8.00 & 8 & 5.90 \\
\hline \multicolumn{7}{|l|}{ Gender } \\
\hline Male & 153 & 58.85 & 72 & 57.60 & 81 & 60.00 \\
\hline Female & 107 & 41.15 & 53 & 42.40 & 54 & 40.00 \\
\hline \multicolumn{7}{|l|}{ Education } \\
\hline Completed primary and secondary education & 32 & 12.31 & 15 & 12.00 & 17 & 12.59 \\
\hline Undergraduate and graduate degree education & 228 & 87.69 & 110 & 88.00 & 118 & 87.41 \\
\hline \multicolumn{7}{|l|}{ Monthly household income } \\
\hline Below $€ 600$ & 25 & 9.62 & 11 & 8.80 & 14 & 10.37 \\
\hline$€ 600-€ 999$ & 18 & 6.92 & 9 & 7.20 & 9 & 6.67 \\
\hline$€ 1,000-€ 1,499$ & 54 & 20.77 & 28 & 22.40 & 26 & 19.26 \\
\hline$€ 1,500-€ 2,500$ & 114 & 43.85 & 53 & 42.40 & 61 & 45.19 \\
\hline More than $€ 2,500$ & 49 & 18.85 & 24 & 19.20 & 25 & 18.52 \\
\hline
\end{tabular}


Table 3

Means and standard deviations of booking intention by scenario

\begin{tabular}{ccccccc}
\hline & \multicolumn{3}{c}{ Experiment $1(N=125)$} & \multicolumn{3}{c}{ Experiment 2 $(N=135)$} \\
\cline { 2 - 7 } & Medium & Meliá & Difference & Medium & Meliá & Difference \\
\hline Initial Condition & $4.08(0.97)$ & $2.41(1.15)$ & $1.67(1.69)$ & $4.30(0.87)$ & $2.24(1.07)$ & $2.06(1.48)$ \\
\hline Scenario 1 & $3.86(1.00)$ & $2.78(1.24)$ & $1.08(1.81)$ & $2.25(1.24)$ & $4.08(0.89)$ & $-1.83(1.69)$ \\
\hline Scenario 2 & $4.16(0.95)$ & $1.85(1.04)$ & $2.31(1.60)$ & $4.30(0.85)$ & $2.15(1.00)$ & $2.15(1.40)$ \\
\hline Scenario 3 & $4.46(0.87)$ & $2.17(1.06)$ & $2.29(1.59)$ & $4.46(0.78)$ & $2.02(1.00)$ & $2.44(1.33)$ \\
\hline Scenario 4 & $3.30(1.05)$ & $2.74(1.12)$ & $0.56(1.83)$ & $3.65(1.10)$ & $2.53(1.14)$ & $1.12(1.91)$ \\
\hline
\end{tabular}


Table 4

Effects of changes in ratings on booking intention: mean differences and $p$-values

\begin{tabular}{|c|c|c|c|c|c|c|c|c|}
\hline & \multicolumn{4}{|c|}{ Experiment $1(N=125)$} & \multicolumn{4}{|c|}{ Experiment $2(N=135)$} \\
\hline & \multicolumn{2}{|c|}{$\begin{array}{c}\text { Highest average } \\
\text { rating }\end{array}$} & \multicolumn{2}{|c|}{$\begin{array}{l}\text { Lowest average } \\
\text { rating }\end{array}$} & \multicolumn{2}{|c|}{$\begin{array}{c}\text { Highest average } \\
\text { rating }\end{array}$} & \multicolumn{2}{|c|}{$\begin{array}{c}\text { Lowest average } \\
\text { rating }\end{array}$} \\
\hline & MED & MEL & MED & MEL & MED & MEL & MED & MEL \\
\hline Initial Condition MED & $\begin{array}{c}0.38 \\
(0.00) \\
\end{array}$ & & $\begin{array}{l}-0.78 \\
(0.00) \\
\end{array}$ & & $\begin{array}{c}0.16 \\
(0.00) \\
\end{array}$ & & $\begin{array}{l}-0.65 \\
(0.00) \\
\end{array}$ & \\
\hline Initial Condition MEL & & $\begin{array}{c}0.37 \\
(0.00)\end{array}$ & & $\begin{array}{l}-0.56 \\
(0.00)\end{array}$ & & $\begin{array}{c}1.84 \\
(0.00)\end{array}$ & & $\begin{array}{l}-0.09 \\
(0.25)\end{array}$ \\
\hline
\end{tabular}

Notes: MED-Medium Hotel; MEL-Meliá Hotel. Initial condition: 79\% thumb rating and 4.0 bubble rating. 
Table 5

Effects of average ratings on booking intention moderated by brand image

\section{Experiment $1(N=125)$}

Hotels mean difference (SD) Scenarios mean difference (SD) $\quad t$ value ( $p$ value)

\begin{tabular}{|c|c|c|c|}
\hline Scenario 1 & $1.08(1.81)$ & \multirow{2}{*}{$1.21(1.32)$} & \multirow{2}{*}{$10.22(0.00)$} \\
\hline Scenario 3 & $2.29(1.59)$ & & \\
\hline Scenario 2 & $2.31(1.60)$ & \multirow{2}{*}{$1.75(1.57)$} & \multirow{2}{*}{$12.44(0.00)$} \\
\hline Scenario 4 & $0.56(1.83)$ & & \\
\hline \multicolumn{4}{|c|}{ Experiment $2(N=135)$} \\
\hline
\end{tabular}

Hotels mean difference (SD) Scenarios mean difference (SD) $\quad t$ value ( $p$ value)

\begin{tabular}{cccc}
\hline Scenario 1 & $-1.83(1.69)$ & $4.27(2.65)$ & $18.71(0.00)$ \\
\hline Scenario 3 & $2.44(1.33)$ & $1.03(1.82)$ & $6.57(0.00)$ \\
\hline Scenario 2 & $2.15(1.40)$ & $1.12(1.91)$ & \\
\hline Scenario 4 & &
\end{tabular}

